\title{
Transport of Volatile Organic Compounds Across the Capillary Fringe
}

\author{
KathleEn A. MCCARTHY ${ }^{1}$ and RichaRd L. Johnson
}

\author{
Department of Environmental Science and Engineering, Oregon Graduate Institute, Beaverton
}

\begin{abstract}
Physical experiments were conducted to investigate the transport of a dissolved volatile organic compound (trichloroethylene, TCE) from shallow groundwater to the unsaturated zone under a variety of conditions including changes in the soil moisture profile and water table position. Experimental data indicated that at moderate groundwater velocities $(0.1 \mathrm{~m} / \mathrm{d})$, vertical mechanical dispersion was negligible and molecular diffusion was the dominant vertical transport mechanism. Under these conditions, TCE concentrations decreased nearly 3 orders of magnitude across the capillary fringe and soil gas concentrations remained low relative to those of underlying groundwater. Data collected during a water table drop showed a short-term increase in concentrations throughout most of the unsaturated zone, but these concentrations quickly declined and approached initial values after the water table was returned to its original level. In the deep part of the unsaturated zone, the water table drop resulted in a long-term decrease in concentrations, illustrating the effects of hysteresis in the soil moisture profile. A two-dimensional random walk advection-diffusion model was developed to simulate the experimental conditions, and numerical simulations agreed well with experimental data. A simpler, one-dimensional finite-difference diffusion-dispersion model was also developed. Onedimensional simulations based on molecular diffusion also agreed well with experimental data. Simulations which incorporated mechanical dispersion tended to overestimate flux across the capillary fringe. Good agreement between the one- and two-dimensional models suggested that a simple, one-dimensional approximation of vertical transport across the capillary fringe can be useful when conditions are appropriate.
\end{abstract}

\section{INTRODUCTION}

Mass transport between the unsaturated and saturated zones plays an important role in controlling many subsurface processes. This is particularly the case for volatile organic contaminants (VOCs). Because many contaminant sources occur at the land surface or within the unsaturated zone, mass transport from the unsaturated zone to the saturated zone is a common mechanism of groundwater contamination. Conversely, volatilization of contaminants from groundwater and subsequent transport to the atmosphere can provide a natural remediation pathway. Microorganisms active in the saturated zone may also rely on this transport pathway either to provide oxygen or other compounds essential for their growth, or to rid their environment of potentially toxic metabolic products. Finally, the success of technologies such as soil gas monitoring to detect underlying groundwater contamination and enhanced in situ volatilization to remediate existing pollution problems requires quantitative knowledge of the movement of contaminants across the interface between the saturated and unsaturated zones.

In order to better understand mass transfer between the saturated and unsaturated zones, it is necessary to more clearly understand the nature of the interface between the two zones (Figure 1). This interface, referred to subsequently as the "capillary fringe," includes both the tensionsaturated porous medium above the water table (in which water pressure is less than atmospheric) and the deep part of the unsaturated zone (in which soil moisture content varies as a function of depth). Because moisture content and hence air-filled porosity in this region vary with depth, the cross-

\footnotetext{
${ }^{1}$ Also at Water Resources Division, U.S. Geological Survey, Portland, Oregon.

Copyright 1993 by the American Geophysical Union.

Paper number 93WR00098. 0043-1397/93/93WR-00098\$05.00
}

sectional area available for mass flux and the pathway tortuosity for both phases vary. The variation in water-filled porosity also produces a variation in relative permeability for the aqueous phase and therefore leads to changes in water velocity with depth.

The processes involved in mass exchange between the saturated and unsaturated zones include aqueous and gas phase molecular diffusion, mechanical dispersion, aqueous and gas phase advection, and partitioning among the aqueous, gas, and solid phases. The extent to which each of these processes contributes to mass transfer between the saturated and unsaturated zones depends on both the properties of the compound and the conditions within the subsurface. Although numerous investigators have reported field data that indicate exchange between the two zones can be significant [Swallow and Gschwend, 1983; Lappala and Thompson, 1983; Hinchee and Reisinger, 1985; Davis et al., 1986; Davis and Matthews, 1989; Pionke and Glotfelty, 1990], few have specifically examined the transport mechanisms involved.

Swallow and Gschwend [1983] formulated a onedimensional steady state mathematical model to describe the volatilization of compounds from unconfined aquifers. The three-box model was based on vertical dispersion in the saturated zone, Henry's law phase partitioning at the interface, and gas phase diffusion in the unsaturated zone. In an associated laboratory experiment they measured dye dispersion below the water table and calculated a vertical dispersivity of $0.0033 \mathrm{~m}$. In another experiment, they measured concentration gradients resulting - from a saturated-zone source of trichloroethylene (TCE), but were unable to detect TCE in the unsaturated zone, possibly due to the limited scale of their physical model. They therefore used mass balance calculations to estimate flux through the unsaturated zone. By comparing model results with flux estimates from the experiments, they concluded that their model adequately described the vertical transport of TCE from groundwater.

Barber et al. [1990] investigated the transport of methane 


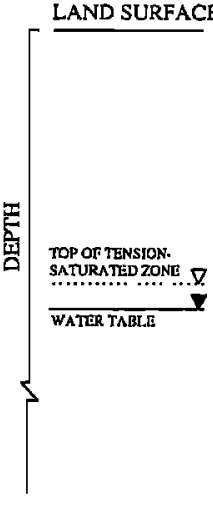

(a)

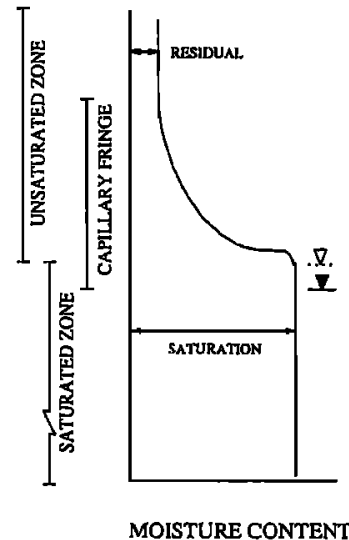

(b) (c)



Fig. 1. The shallow subsurface environment: $(a)$ hydrologic components, $(b)$ soil moisture content as a function of depth, and (c) pressure head as a function of depth [after Freeze and Cherry, 1979].

from groundwater to the unsaturated zone at a field site and concluded that the process was dominated by diffusion and that diffusivity in the saturated zone was the limiting mechanism. However, due to the scale of their field study, a detailed investigation of the interface between the saturated and unsaturated zones was not possible. Using a simple, one-dimensional diffusion model, they obtained reasonably good agreement with their data, but changes in diffusivity within the unsaturated zone were neglected.

Numerical modeling of transport in and exchange between the saturated and unsaturated zones poses significant problems resulting from (1) the abrupt change in spatial and temporal scales of transport at the interface between the zones; (2) the large difference between horizontal (usually advection dominated) and vertical (usually diffusion/ dispersion dominated) transport parameters in the saturated zone; and (3) the paucity of data available on vertical dispersion, particularly above the water table, and mass exchange rates between the two zones. As a result, the few existing models that incorporate mass exchange between the zones rely on assumptions that have not previously been validated in the laboratory or in the field.

In a study of oxygen-limited hydrocarbon biodegradation, Borden and Bedient [1986] modeled the exchange of hydrocarbons and oxygen between the saturated and unsaturated zones. In their simulations, it was assumed that the moisture content throughout the unsaturated zone was constant and that the interface between the unsaturated and saturated zones occurred at the water table. Thus the zone of increasing water content in the deep unsaturated zone and the zone of tension-saturated porous medium above the water table were not accounted for. It was further assumed that soil gas concentrations immediately above the water table were in equilibrium with groundwater immediately below the water table.

Sleep and Sykes [1989] developed a numerical model to simulate the transport of volatile organic compounds in both the saturated and unsaturated zones. Their model allowed for variations in water content near the water table, so diffusive vapor transport could be accurately represented in that region. To simulate the movement of volatile organics across the interface between the saturated and unsaturated zones, they used a range of mass transfer coefficients. They also modeled infiltration of water into the subsurface, partitioning of the volatile organics between the vapor and infiltrating water phases, and incorporation of the infiltrating water into groundwater. For the conditions simulated, they concluded that aqueous phase transport into the groundwater was the primary transport pathway into the saturated zone.

Mendoza and Frind [1990] reported a model that simulates diffusive and advective vapor transport in unsaturated porous media. As with the model of Sleep and Sykes [1989], their model allows increasing water content and decreased vapor diffusion rates near the water table. Transport from the unsaturated zone to the groundwater was once again simulated using mass transfer coefficients. Mendoza and McAlary [1990] investigated the potential for groundwater contamination resulting from an unsaturated-zone vapor source by using an unsaturated-zone transport model to define the source function for a saturated-zone transport model. In their unsaturated-zone simulations, mass transport at the upper and lower boundaries was governed by mass transfer coefficients and the soil moisture content was assumed to be constant throughout the domain. Their saturated-zone simulations indicate that the potential for groundwater contamination is significant; however, this may be due to the large value used for vertical dispersivity $(0.1 \mathrm{~m})$.

Vertical dispersion has been examined in the field by a number of researchers [e.g., Garabedian et al., 1991; LeBlanc et al., 1991; Rajaram and Gelhar, 1991; also S. Feenstra, unpublished data, 1990]. At groundwater velocities less than $0.5 \mathrm{~m} / \mathrm{d}$ they observed vertical dispersion to be of the order of molecular diffusion, rather than more commonly used values based on dispersivities in the range 0.01-1 $\mathrm{m}$. For reference, at a groundwater velocity of $0.1 \mathrm{~m} / \mathrm{d}$, a



Fig. 2. Schematic drawing of the aquifer model. 


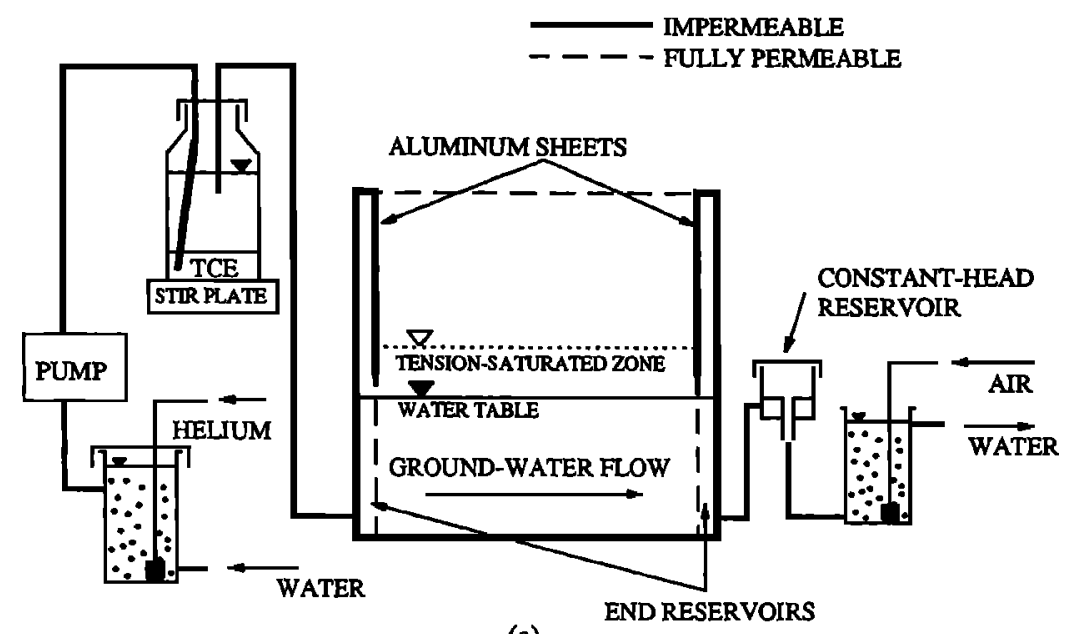

(a)



- SAMPLING PORTS

(b)

Fig. 3. (a) Schematic drawing of the flow system used for the mass transfer experiments. (b) Cross-sectional view showing the locations of selected sampling bundles and ports.

vertical dispersivity of $0.0005 \mathrm{~m}$ results in a vertical dispersion equal in magnitude to molecular diffusion.

The assumption of a constant soil moisture content throughout the unsaturated zone, omission of the tensionsaturated zone, and the use of unrealistically high values of saturated-zone vertical dispersivity all serve to overestimate mass flux between the saturated and unsaturated zones. In addition, few data are available to quantify the rate coefficients commonly used to represent mass exchange at the interface between the zones. The objective of the physical and numerical model studies reported was to use TCE to examine and quantify transport of volatile organic compounds within the capillary fringe under conditions of low groundwater velocity and no infiltration.

\section{Experimental Methods}

\section{Physical Modeling}

The aquifer model used in these experiments was $0.75 \mathrm{~m}$ wide, $1.0 \mathrm{~m}$ long, and $1.0 \mathrm{~m}$ deep (Figure 2). It was constructed with glass bottom and side panels and acrylic sheet end panels, all supported by a steel frame. Rigid screens were installed parallel to and approximately $0.025 \mathrm{~m}$ in from the ends of the model to form end reservoirs (Figure 3). In this way, flow into and out of the model occurred throughout the entire region below the water table. To prevent direct communication between the soil gas of the unsaturated zone and the headspace of the reservoirs, aluminum plates extending from the top of the model to a depth of approximately $0.55 \mathrm{~m}$ were installed at the inner sides of the screens. The outflow port from the downstream reservoir was connected via tubing to an adjustable constant-head reservoir that controlled the water level in the model.

A two-dimensional sampling network was installed along the longitudinal axis of the model. Nine bundles of $1.6-\mathrm{mm}$ outside diameter (o.d.), $0.8-\mathrm{mm}$ inside diameter Teflon tubing attached to $3.2-\mathrm{mm}$ o.d. stainless steel support rods provided 0.1-m horizontal sampling resolution. Each bundle consisted of 20 lengths of tubing, providing $0.03-\mathrm{m}$ vertical sampling resolution in the middle portion of the tank and $0.06-\mathrm{m}$ vertical resolution in the upper and lower parts. The upper end of each tube was fitted with an 18-gauge syringe needle and plugged with a Teflon stopper.

The main part of the aquifer model was carefully filled with type 8 flint shot Ottawa sand in 1-mm horizontal layers. The water level was adjusted to be just below the working surface throughout the filling procedure. As each third of the final depth was achieved, a portable concrete vibrator was used to ensure that sand was packed uniformly into the spaces between the tubing and support rods of the sampling 


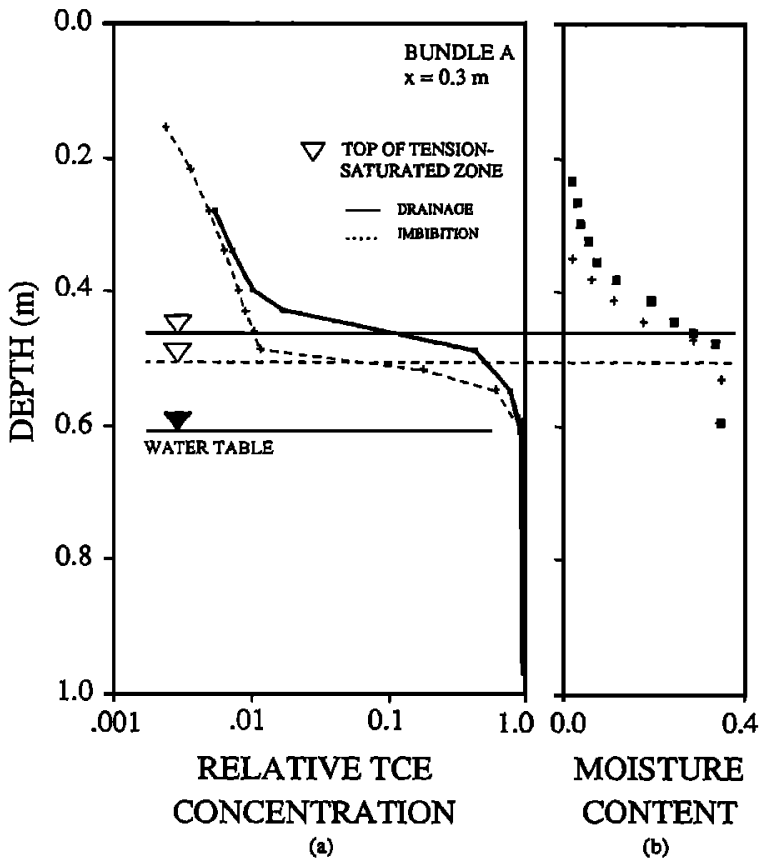

Fig. 4. (a) Steady state profiles of depth versus TCE concentration under drainage (solid squares connected with solid curve) and imbibition (pluses connected with dashed curve) conditions. $(b)$ Moisture content versus depth under drainage (solid squares) and imbibition (pluses) conditions. (Concentrations are reported relative to the maximum concentration at bundle $\mathrm{A}(x=0.3 \mathrm{~m})$.)

bundles. The end reservoirs were filled with pea gravel. The surface of the sand was uncovered during all experiments. Clean, helium-sparged water was then flushed continuously through the entire model for several weeks. The water level was then lowered to a depth of $0.61 \mathrm{~m}$ below the top of the model and clean, helium-sparged water continued to flow through the model for several weeks before the first experiment began.

The flow system used for the mass transfer experiments is shown in Figure $3 a$. A peristaltic pump delivered heliumsparged deionized water to a 2-L glass bottle where it was continuously stirred with TCE. The resulting TCE-saturated aqueous solution then flowed through the aquifer model. Data from three of the nine sampling bundles are reported here. The horizontal and vertical positions of the sampling ports are shown in Figure $3 b$. Bundles $\mathbf{A}, \mathbf{B}$, and $\mathrm{C}$, were located $0.3,0.5$, and $0.7 \mathrm{~m}$, respectively, from the influent reservoir.

The first experiment was designed to investigate the movement of dissolved TCE from the groundwater to the unsaturated zone under drainage conditions (i.e., the "drainage experiment"). Drainage conditions produced a capillary fringe which included a tension-saturated zone that extended approximately $0.14 \mathrm{~m}$ above the water table and a variably saturated zone which extended $0.25 \mathrm{~m}$ above the tensionsaturated zone (Figure $4 b$ ). The average groundwater velocity through the model was maintained at approximately 0.1 $\mathrm{m} / \mathrm{d}$. After 16 days, measured TCE concentrations throughout the model stabilized, indicating steady state conditions had been established. Steady state conditions were maintained for $\mathbf{4 2}$ days.

Following the drainage experiment, a second experiment was conducted to investigate the transport of TCE from groundwater during a water table drop. The water table was lowered an additional $0.15 \mathrm{~m}$ at a rate of $0.05 \mathrm{~m} / \mathrm{d}$ and allowed to remain at that level for 3 days. During this period, TCE concentrations in the saturated and unsaturated zones were monitored.

A third experiment was conducted to examine the movement of TCE from groundwater under imbibition conditions (i.e., the "imbibition experiment"). After the water table drop, the water level was raised back to its original depth of $0.61 \mathrm{~m}$ at a rate of $0.05 \mathrm{~m} / \mathrm{d}$. This resulted in an imbibition capillary fringe in which the tension-saturated zone extended approximately $0.09 \mathrm{~m}$ above the water table. Again, an average groundwater velocity of approximately $0.1 \mathrm{~m} / \mathrm{d}$ was maintained through the model and steady state conditions were reestablished in both the saturated and unsaturated zones in about 10 days. This experiment was continued for 58 days.

At the conclusion of the experiments, soil cores were taken from the aquifer model under both drainage and imbibition conditions. The cores were cut into $3-\mathrm{cm}$ sections for determination of the soil bulk density, porosity, and depth-dependent moisture content.

\section{Sampling and Analyses}

Pore air and water samples were collected by attaching a gastight syringe (Hamilton, Inc., Reno, Nevada) to the needle fitted into the sampling port tubing. Two sampling tube volumes were drawn to purge the sampling line before the sample was collected (purge volumes ranged from 0.2 to $1.1 \mathrm{~mL}$ ).

Aqueous samples $(2.0 \mathrm{~mL})$ were collected from the saturated zone in $5-\mathrm{mL}$ syringes. The samples were placed in 5-mL glass vials fitted with Teflon Mininert valves (Pierce, Rockford, Illinois) and allowed to equilibrate, with periodic vigorous shaking, for a minimum of 1 hour. (Preliminary tests showed that this method resulted in equilibration between the aqueous phase and headspace within $30 \mathrm{~min}$.) A $0.75-\mathrm{mL}$ sample of headspace was then drawn from the vial using a 1-mL gastight syringe and analyzed by gas chromatography (GC). Aqueous phase standards were prepared in 45-mL vials equipped with Mininert valves. The vials were initially cleaned with methanol and rinsed with deionized water. The vials were then weighed, and a known quantity (by weight) of deionized water was injected through the valve. A known quantity (by weight) of a TCE-saturated aqueous stock solution was then injected into the bottom of the vial. The vials were stored in an inverted position and periodically shaken vigorously. Aqueous phase standards were allowed to equilibrate for a minimum of 24 hours before use and were prepared approximately every 3 days.

Soil gas samples $(0.75-\mathrm{mL})$ were collected from the unsaturated zone in $1.0-\mathrm{mL}$ gastight syringes and were analyzed directly by GC. Gas phase standards were prepared in $0.8-\mathrm{L}$ stainless steel canisters equipped with stainless steel bellows valves (Whitey Company, Highland Heights, Ohio). The canisters were initially cleaned by alternately evacuating and pressurizing to $10 \mathrm{~atm}$ with nitrogen gas. A known quantity (by volume) of TCE was then injected into each canister with a gastight syringe. Each canister was then pressurized with nitrogen gas to obtain the desired TCE concentrations. Gas phase standards were prepared approximately. once per month. 
All analyses were performed using a six-port gas-sampling valve connected to a Hewlett-Packard HP 5890 GC (Hewlett-Packard Company, Avondale, Pennsylvania) equipped with a flame ionization detector. Standards were run at the beginning and end of the sampling sessions. The combined coefficient of variation of data from three successive samplings of bundle A over an 8-day period during the drainage experiment was $4.8 \%$. For a 13-day period during the imbibition experiment, the combined coefficient of variation for data collected from bundle $A$ was $7.6 \%$.

\section{REsults AND Discussion}

\section{Drainage Experiment}

During the steady state "drainage experiment," TCE concentrations varied vertically nearly 3 orders of magnitude between the water table and the top of the capillary fringe. The steady state depth versus concentration profile that developed at $0.3 \mathrm{~m}$ into the aquifer model (bundle $\mathrm{A}$ ) is shown as a solid line in Figure $4 a$. Figure $4 b$ shows the corresponding soil moisture profile. A significant change in the vertical concentration gradient occurred near the water table, resulting in a pronounced gradient across the tensionsaturated zone. Moving upward through the capillary fringe, concentrations continued to drop, but at a decreasing rate. A nonlinear steady state concentration gradient such as this is to be expected in a region of changing water content. This can be seen from the one-dimensional form of Fick's first law:

$$
F_{z}=-\left[\theta_{w} D_{e w}\left(\frac{\partial C_{w}}{\partial z}\right)+\theta_{g} D_{e g}\left(\frac{\partial C_{g}}{\partial z}\right)\right]
$$

where $F_{z}$ is the vertical mass flux; $\theta_{w}$ and $\theta_{g}$ are the waterand gas-filled porosities; $D_{e w}$ and $D_{e g}$ are the effective diffusion coefficients, in the water and gas phases, for the species of interest; and $\partial C_{w} / \partial z$ and $\partial C_{g} / \partial z$ are the vertical concentration gradients in the water and gas phases. If molecular diffusion was the dominant vertical transport mechanism (as will be shown in the numerical modeling section) and the gas- and water-filled porosities changed with depth (as shown in Figure $4 b$ ), it is clear from (1) that a constant vertical flux would occur only if the concentration gradients changed with depth.

The observation that the bulk of the concentration gradient (i.e., $-90 \%$ concentration decrease) occurred in the tension-saturated zone indicates that (1) the flux of VOCs from the groundwater will be controlled by aqueous phase processes and (2) mixing within the shallow groundwater zone must be relatively weak (otherwise the depth to which concentrations would be depleted would be greater.) The implication of these two observations is that the flux of VOCs from the saturated zone, as described by (1), will be small.

\section{Water Table Drop Experiment}

Changes in TCE concentration that occurred at four different depths during the water table drop experiment are shown in Figure 5. At depths of $0.16,0.28$, and $0.40 \mathrm{~m}$ in the unsaturated zone (Figure $5 a$ ), concentrations rose markedly and had approximately doubled by the time the water table reached its lowest level. This can be explained by the

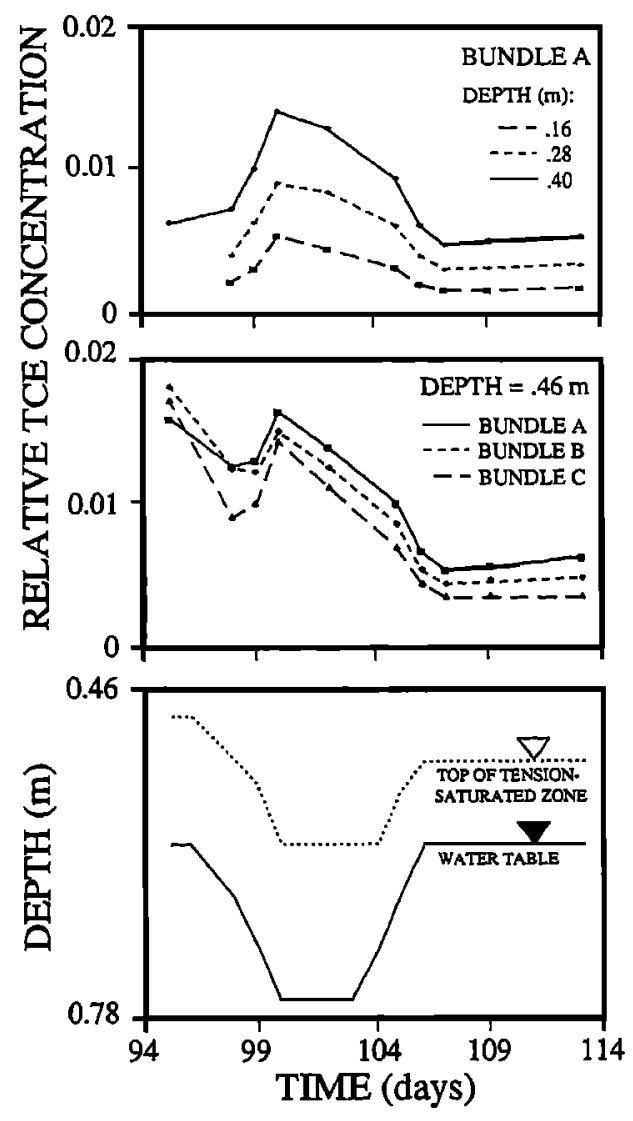

(a)

(b)

Fig. 5. Water table drop experiment: (a) TCE concentration versus time at sampling bundle A $(x=0.3 \mathrm{~m}),(b)$ TCE concentration versus time at a depth of $0.46 \mathrm{~m}$, and (c) water level versus time. (Concentrations are reported relative to influent concentration.)

redistribution of water and soil gas which occurred over the course of this experiment. In response to the declining water table, the water content in what had originally been the capillary fringe decreased and water which had previously been part of the saturated zone (and hence contained high concentrations of TCE) was increasingly exposed to the gas phase. The gas and water phases quickly approached concentration equilibrium, resulting in elevated soil gas concentrations. However, because transport in the gas phase is rapid, the high concentrations quickly dissipated. Within 1 day, elevated concentrations began falling toward previous levels. After the water table was raised to its original position, TCE concentrations throughout most of the unsaturated zone returned to near-initial values.

In contrast to the shallow unsaturated zone, TCE concentrations at a depth of $0.46 \mathrm{~m}$ showed an overall decrease during the water table drop and did not return to initial values (Figure $5 b \overline{\text { ) }}$. This behavior can also be explained by the soil moisture profile. Before the water table drop, the 0.46-m sampling ports were less than $0.01 \mathrm{~m}$ above the top of the tension-saturated zone and thus in a region of very high moisture content. Because the soil moisture profile is not linear, the relative increase in gas-filled porosity and, hence, gas phase transport was much greater at this depth than at shallower depths. As illustrated in Figure $5 b$, the lowered concentrations persisted even after the water table was raised to its original level. This can also be attributed to the soil moisture profile. The vertical extent of the imbibition 
tension-saturated zone that developed after the water table drop was approximately $0.05 \mathrm{~m}$ less than that of the previous drainage tension-saturated zone (Figure $5 c$ ). As a consequence, the moisture content at a depth of $0.46 \mathrm{~m}$ decreased from approximately 0.29 (prior to the water table drop) to approximately 0.23 (after the water table was raised to its original position). As shown by K. A. McCarthy and R. J. Johnson (Measurement of trichloroethylene diffusion in soil with a continuously-varying moisture content, submitted to Journal of Contaminant Hydrology, 1993) this corresponds to more than an order of magnitude increase in the effective diffusion coefficient.

\section{Imbibition Experiment}

Similar to the "drainage experiment," data from the "imbibition experiment" were also characterized by a pronounced concentration gradient within the tension-saturated zone and a decrease in concentration of nearly 3 orders of magnitude between the water table and the top of the capillary fringe (Figure $4 a$, dashed curve). However, in contrast to the drainage case, concentrations above the water table dropped more abruptly. This is consistent with what would be expected based on the imbibition moisture content profile (Figure $4 b$ ), which is characterized by a less extensive tension-saturated zone within the capillary fringe.

\section{Numerical Modeling}

\section{Two-Dimensional Advection-Diffusion Model}

The physical model experiments discussed previously were simulated using a two-dimensional, advection-diffusion numerical model. As mentioned earlier, the spatial and temporal scales of transport within the capillary fringe span more than 3 orders of magnitude. This necessitates prohibitive discretization in standard finite-difference and finiteelement numerical models in order to prevent numerical dispersion. To partially overcome discretization requirements, random walk particle tracking was chosen as the numerical technique for this model. The model development is presented in detail by R. L. Johnson et al. (Development of a two-dimensional particle-tracking model to simulate transport across the capillary fringe, submitted to Water Resources Research, 1993; hereinafter Johnson et al., submitted manuscript, 1993) and is discussed only briefly here.

For a three-phase system in which aqueous and gas phase diffusion and horizontal groundwater advection are the dominant transport mechanisms, the transport equation may be written

$$
\begin{aligned}
\frac{\partial C_{T}}{\partial t}= & \frac{\partial}{\partial x}\left[\left(D_{f w} \theta_{w} \tau_{w}\right)\left(\frac{\partial C_{w}}{\partial x}\right)\right]+\frac{\partial}{\partial x}\left[\left(D_{f g} \theta_{g} \tau_{g}\right)\left(\frac{\partial C_{g}}{\partial x}\right)\right] \\
& -\frac{\partial}{\partial x}\left[v_{w} \theta_{w} C_{w}\right]+\frac{\partial}{\partial z}\left[\left(D_{f w} \theta_{w} \tau_{w}\right)\left(\frac{\partial C_{w}}{\partial z}\right)\right] \\
& +\frac{\partial}{\partial z}\left[\left(D_{f g} \theta_{g} \tau_{g}\right)\left(\frac{\partial C_{g}}{\partial z}\right)\right]
\end{aligned}
$$

where

$$
C_{T}=C_{w} \theta_{w}+C_{g} \theta_{g}+C_{s} \rho_{b}
$$

In these expressions, $C_{T}$ is the total concentration; $t$ is time; $x$ and $z$ are the horizontal (longitudinal) and vertical coordinates; $D_{f w}$ and $D_{f g}$ are the free water and free gas diffusion coefficients; $\theta_{w}$ and $\theta_{g}$ are the water- and gas-filled porosities; $\tau_{w}$ and $\tau_{g}$ are the water and gas phase tortuosity factors; $C_{w}, C_{g}$, and $C_{s}$ are the water, gas, and solid phase concentrations; $v_{w}$ is the groundwater velocity; and $\rho_{b}$ is the soil bulk density. If equilibrium phase partitioning is assumed,

$$
\begin{aligned}
& C_{g}=H C_{w} \\
& C_{s}=K_{d} C_{w}
\end{aligned}
$$

where $H$ is Henry's constant and $K_{d}$ is the soil water partition coefficient, both in their dimensionless forms. Using the relationships given by (3), (2a) may be rewritten as

$$
\begin{aligned}
\frac{\partial C_{T}}{\partial t}=\frac{\partial}{\partial x}\left[\left(D^{*}\right)\left(\frac{\partial C_{w}}{\partial x}\right)\right]-\frac{\partial}{\partial x} & {\left[v_{w} \theta_{w} C_{w}\right] } \\
& +\frac{\partial}{\partial z}\left[\left(D^{*}\right)\left(\frac{\partial C_{w}}{\partial z}\right)\right]
\end{aligned}
$$

where

$$
D^{*}=D_{f w} \theta_{w} \tau_{w}+D_{f g} \theta_{g} \tau_{g} H
$$

As discussed by Johnson et al. (submitted manuscript, 1993), in order to satisfy the requirements of particletracking theory, the governing transport equation ( $4 a$ ) must be expressed in the form of the Ito-Fokker-Planck equation. Appropriate rearrangement leads to

$$
\begin{gathered}
\frac{\partial C_{T}}{\partial t}=\frac{\partial^{2}}{\partial x^{2}}\left(D^{*} R C_{T}\right)-\frac{\partial}{\partial x}\left[R C_{T}\left(\frac{\partial D^{*}}{\partial x}\right)\right]-\frac{\partial}{\partial x}\left(v_{w} \theta_{w} R C_{T}\right) \\
+\frac{\partial^{2}}{\partial z^{2}}\left(D^{*} R C_{T}\right)-\frac{\partial}{\partial z}\left[R C_{T}\left(\frac{\partial D^{*}}{\partial z}\right)\right]
\end{gathered}
$$

where

$$
R=\left(\theta_{w}+\theta_{g} H+K_{d} p_{b}\right)^{-1}
$$

The two-dimensional numerical model was based on $(5 a)$.

For the simulations presented here, tortuosity factors for each phase were calculated using the method of Millington [1959]:

$$
\tau_{i}=\theta_{i}^{7 / 3} / \theta_{T}^{2}
$$

where $\theta_{T}$ is total porosity. The values used for porosity, bulk density, and depth-dependent soil moisture content were those measured from the soil cores taken from the aquifer model. The values used for free water and free gas diffusion coefficients, Henry's constant, and the soil water partition coefficient are given in Table 1. A rectangular domain was defined to approximate the experimental conditions (Figure 3). Data collected from sampling bundle $A$ were used to define a constant-flux upstream boundary at $x=0.3 \mathrm{~m}$. The top boundary $(z=0.0 \mathrm{~m})$ was open, and the bottom boundary $(z=1.0 \mathrm{~m})$ was reflective. The downstream boundary $(x=1.0 \mathrm{~m})$ was reflective above $z=0.55 \mathrm{~m}$ and open below this level. The length of time simulated was 4 
days, which corresponded to $0.4 \mathrm{~m}$ of horizontal groundwater movement in the physical model.

The results from four identical simulations are shown superposed in Figure 6. These results are vertical profiles of concentration from $0.4 \mathrm{~m}$ downstream of the constant-flux boundary and represent the simulated concentrations at sampling bundle $C$. The experimental data shown in Figure 6 are from sampling bundle $C$ and were collected 4 days after the data used as initial conditions (bundle $A$ ). The model results agree well with the experimental data considering that no fitting parameters were used in the simulations. The values used for all variables were either experimentally determined or obtained from the literature. The important observation to be made from these simulations as well as the experimental data is that a sharp concentration gradient is maintained across the capillary fringe during the 4 days of transport between bundles $A$ and $C$. As will be discussed in the next section, this can occur only if vertical dispersion is of the order of aqueous phase molecular diffusion.

\section{One-Dimensional Diffusion-Dispersion Model}

The particle-tracking model provides an accurate means for simulating transport across the capillary fringe while partially overcoming the discretization requirements of standard finite-difference and finite-element models. However, the large changes in concentration that occur across the capillary fringe necessitate the use of very large numbers of particles in order to obtain meaningful results. As a consequence, the model is numerically very intensive. A simpler means of simulating transport across the capillary fringe is therefore desirable.

In the physical experiments presented here, the groundwater velocity was low and flow was horizontal. In addition, horizontal concentration gradients were small. This is illustrated in Figure $5 b$, which shows that concentrations decreased only slightly between sampling bundles $\mathrm{A}$ and $\mathrm{C}$. It was hypothesized that, under these conditions, vertical transport through the capillary fringe was not significantly affected by horizontal processes in the unsaturated zone and could therefore be adequately approximated in one dimension where the frame of reference moves along with the flowing groundwater. To test this hypothesis, a onedimensional finite-difference model was developed.

For a three-phase system in which molecular diffusion and aqueous phase mechanical dispersion are the dominant vertical transport mechanisms, the one-dimensional form of the transport equation is

TABLE 1. Numerical Model Input Parameters for TCE at $20^{\circ} \mathrm{C}$

\begin{tabular}{ll}
\hline \multicolumn{1}{c}{ Parameter } & \multicolumn{1}{c}{ Value } \\
\hline Free water diffusion coefficient, $\mathrm{m}^{2} / \mathrm{s}$ & $9.1 \times 10^{-10 a}$ \\
Free gas diffusion coefficient, $\mathrm{m}^{2} / \mathrm{s}$ & $8.3 \times 10^{-6 b}$ \\
Henry's constant, dimensionless & $0.38 c$ \\
Soil water partition coefficient, dimensionless & $0.126^{c}$ \\
\hline${ }^{a}$ Estimated by the Hayduk and Laudie method [Lyman et al., \\
1982]. \\
b Estimated by the Fuller, Schettler, and Giddings Method [Lay- \\
man et al. 1982]. \\
c From Mabey et al. [1982].
\end{tabular}



Fig. 6. Superposed results from the two-dimensional numerical model (curves) and experimental data (symbols) from sampling bundle $C(x=0.7 \mathrm{~m})$. (Concentrations are reported relative to the maximum concentration at bundle $\mathrm{A}(x=0.3 \mathrm{~m})$.)

$$
\begin{aligned}
\frac{\partial C_{T}}{\partial t}=\frac{\partial}{\partial z}\left[\left(D_{f w}+\alpha v_{w}\right) \theta_{w} \tau_{w}\left(\frac{\partial C_{w}}{\partial z}\right)\right] & \\
& +\frac{\partial}{\partial z}\left[D_{f g} \theta_{g} \tau_{g}\left(\frac{\partial C_{g}}{\partial z}\right)\right]
\end{aligned}
$$

where $\alpha$ is mechanical dispersivity and all other variables are as defined in the previous section. Recalling ( $2 b$ ) and (3), and assuming $\theta_{w}, H, \theta_{g}, \rho_{b}$, and $K_{d}$ do not change over time, (7) may be written

$$
\frac{\partial C_{w}}{\partial t}=\frac{\frac{\partial}{\partial z}\left[\left[\left(D_{f w}+\alpha v_{w}\right) \theta_{w} \tau_{w}+D_{f g} \theta_{g} \tau_{g} H\right]\left(\frac{\partial C_{w}}{\partial z}\right)\right]}{\left(\theta_{w}+\theta_{g} H+\rho_{b} K_{d}\right)}
$$

The one-dimensional numerical model was based on a finitedifference approximation of (8) and incorporated Dirichlet boundary conditions.

For the simulations presented, tortuosity factors were again calculated using (6), and the values used for all other variables were the same as those used in the twodimensional simulations. Data collected from sampling bundle A were used as initial conditions, and the length of time simulated was once again 4 days.

The results from three simulations of the drainage experiment are shown in Figure 7 along with the experimental data. The experimental data points shown are the same as those shown in Figure 6, collected from sampling bundle $C 4$ days after the data used as initial conditions. The solid line in Figure 7 is the result of a simulation based on molecular diffusion alone (dispersivity equal to 0 ). The dotted line is the result of a simulation which incorporated a saturated-zone dispersivity of $0.001 \mathrm{~m}$, and the dashed line is the result of a simulation which incorporated a saturated-zone dispersivity of $0.01 \mathrm{~m}$. (These data are similar to results obtained with the 


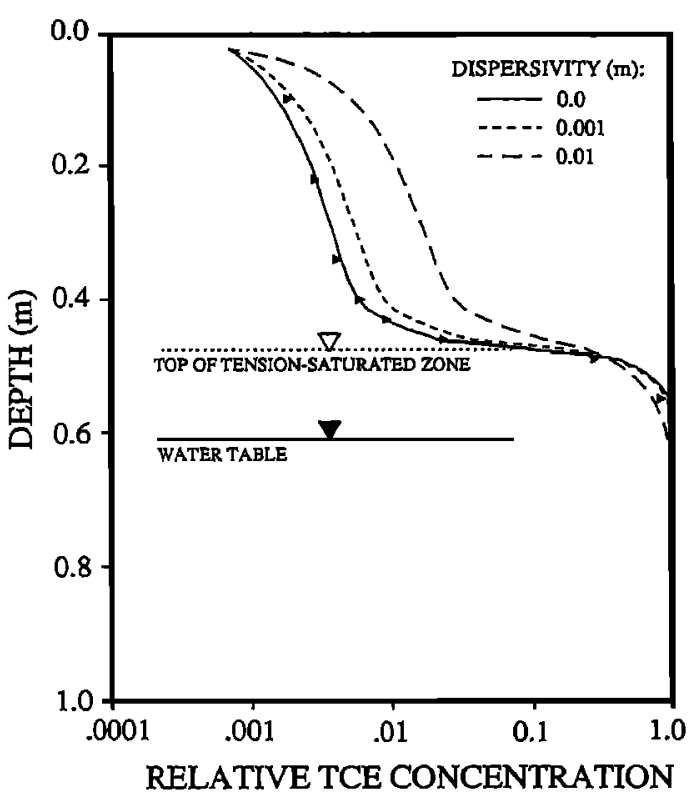

Fig. 7. Results from the one-dimensional numerical model (curves) and experimental data (symbols) from sampling bundle $\mathrm{C}$ ( $x$ $=0.7 \mathrm{~m}$ ). (Concentrations are reported relative to the maximum concentration at bundle $A(x=0.3 \mathrm{~m})$.)

two-dimensional model in which the aqueous diffusion coefficient was increased to simulate mechanical dispersion.)

The similarity between the experimental data and the numerical model results based on molecular diffusion, and the differences between the data and the cases in which dispersion was included, indicate that molecular diffusion is the dominant transport process responsible for mass exchange between the saturated and unsaturated zones under the conditions tested. Using a saturated-zone mechanical dispersivity of $0.01 \mathrm{~m}$ greatly overestimated vertical mass transport. This is consistent with recent field observations of vertical dispersion at similar groundwater velocities [Garabedian et al., 1991; Rajaram and Gelhar, 1991; also S. Feenstra, unpublished data, 1990]. For the experimental conditions, even a mechanical dispersivity of $0.001 \mathrm{~m}$ overestimated flux to the unsaturated zone.

The agreement between the experimental data and the results of the one-dimensional model indicates that the physical experiment was adequately approximated in one dimension. This suggests that a simple, one-dimensional approximation of vertical transport across the capillary fringe can be useful, at least in a qualitative sense, when conditions are appropriate. For many cases in which groundwater velocities are low, flow is predominantly horizontal, and horizontal concentration gradients are small, a onedimensional approximation may be adequate. Because the one-dimensional model does not allow for lateral transport, the condition of small horizontal concentrations gradients is critical. This condition will often be satisfied, however, when depths are small relative to the lateral extent of the species of interest. For example, transport of oxygen from the atmosphere to groundwater, or volatilization from within a shallow, laterally extensive groundwater plume will not typically produce strong horizontal concentration gradients.

\section{Conclusions}

In the mass transfer experiments described above, strong vertical concentration gradients developed in the capillary fringe and very low concentrations were observed in the unsaturated zone. Because gas phase diffusion coefficients are approximately 4 orders of magnitude greater than aqueous phase diffusion coefficients, unsaturated-zone transport of TCE was relatively rapid. This maintained soil gas concentrations at low levels and resulted in large concentration gradients in the tension-saturated zone. TCE concentrations decreased nearly 3 orders of magnitude between the water table and the top of the capillary fringe. This sharp drop in concentration indicates that the vertical mixing process in the aqueous phase is weak, a conclusion which is supported by the mathematical modeling.

Data from the water table drop experiment illustrate two mechanisms that affected transport from the saturated zone to the unsaturated zone during a water table fluctuation. First, as the water table dropped, the soil moisture profile partially drained. As water-filled porosity decreased and gas-filled porosity increased in the new capillary fringe, water which had previously been part of the saturated zone (and hence contained high concentrations of TCE) was increasingly exposed to the gas phase. The gas and water phases quickly approached concentration equilibrium, and soil gas concentrations increased. However, because transport in the gas phase is rapid, the high concentrations quickly dissipated. This was the dominant effect observed throughout most of the unsaturated zone. A second effect was observed when the water table was returned to its original position. Due to the effects of hysteresis in the soil moisture profile, the vertical extent of the tension-saturated zone was reduced by approximately $0.05 \mathrm{~m}$ after the water table rise. As a result, the reduced concentrations deep in the unsaturated zone persisted even after the water table was returned to its original level. This has implications for field work where the position of the water table is routinely monitored, but the extent of the tension-saturated zone and the effects of hysteresis are generally unknown.

The agreement between experimental data and the numerical model simulations based on molecular diffusion was very good. This indicates that at low groundwater velocities (e.g., $0.1 \mathrm{~m} / \mathrm{d}$ ) and in the absence of infiltration, aqueous phase molecular diffusion, rather than mechanical dispersion, is the dominant mechanism for mass transfer between groundwater and the unsaturated zone. The agreement between the one-dimensional diffusion model and the two dimensional advection-diffusion model suggests that vertical transport may be adequately simulated with a onedimensional diffusion model when the conditions are appropriate. Such conditions include low groundwater velocities, predominantly horizontal flow, and weak horizontal concentration gradients.

The conclusion that aqueous phase diffusion controls mass transport from the saturated zone to the unsaturated zone has a number of important implications, including (1) mass flux from the groundwater zone will be relatively small and, even after very long transport times, will be confined to the uppermost part of the saturated zone; (2) numerical simulations that incorporate vertical mechanical dispersion in the saturated zone, particularly above the water table, may significantly overestimate the importance of mass transfer 
across the capillary fringe; (3) soil gas concentrations in the unsaturated zone are strongly dependent upon moisture conditions in the porous medium and the physical properties of the material being transported; and (4) as the result of the third implication, the relationship between groundwater concentrations and soil gas concentrations is not straightforward.

Acknowledgments. This work was supported in part by the U.S. Geological Survey under Award 14-08-0001-G1917 and by the University Consortium Solvents-In-Groundwater Research Program, sponsored by Giba-Geigy Corporation, General Electric Corporation, Dow Chemical Corporation, Eastman Kodak Corporation, and Boeing Corporation. The use of product names in this paper is for identification purposes only and does not constitute endorsement by the Oregon Graduate Institute or the U.S. Geological Survey.

\section{REFERENCES}

Barber, C., G. B. Davis, D. Briegel, and J. K. Ward, Factors controlling the concentration of methane and other volatiles in groundwater and soil-gas around a waste site, J. Contam. Hydrol. , 5, 155-169, 1990.

Borden, R. C., and P. B. Bedient, Transport of dissolved hydrocarbons influenced by oxygen-limited biodegradation, 1, Theoretical development, Water Resour. Res., 22, 1973-1982, 1986.

Davis, G. B., B. Math, and C. Barber, Modeling the volatilization of methane from contaminated groundwaters, paper presented at Conference on Water Quality Modelling in the Inland Natural Environment, Br. Hydromech. Res. Assoc., Bournemouth, England, June 10-13, 1986.

Davis, R. W., and E. W. Matthews, Chloroform contamination in part of the alluvial aquifer, southwest Louisville, Kentucky, U.S. Geol. Surv. Water Supply Pap., 2202, 1989.

Freeze, R. A., and J. A. Cherry, Groundwater, 604 pp., PrenticeHall, Englewood Cliffs, N. J., 1979.

Garabedian, S. P., D. R. LeBlanc, L. W. Gelhar, and M. A. Celia, Large-scale natural gradient tracer test in sand and gravel, Cape Cod, Massachusetts, 2, Analysis of spatial moments for a nonreactive tracer, Water Resour. Res., 27, 911-924, 1991.

Hinchee, R. E., and H. J. Reisinger, Multi-phase transport of petroleum hydrocarbons in the subsurface environment: Theory and practical application, paper presented at NWWA/API Conference on Petroleum Hydrocarbons and Organic Chemicals in Ground Water: Prevention, Detection and Restoration, Natl. Well Water Assoc./Am. Pet. Inst., Houston, Tex., Nov. 13-15, 1985.

Lappala, E. G., and G. M. Thompson, Detection of groundwater contamination by shallow soil gas sampling in the vadose zone, paper presented at NWWAAPI Conference on Characterization and Monitoring of the Vadose Zone, Natl. Well Water Assoc./ Am. Pet. Inst., Las Vegas, Nev., Dec. 1983.

LeBlanc, D. R., S. P. Garabedian, K. M. Hess, L. W. Gelhar, R. D. Quadri, K. G. Stollenwerk, and W. W. Wood, Large-scale natural gradient tracer test in sand and gravel, Cape Cod, Massachusetts, 1, Experimental design and observed tracer movement, Water Resour. Res., 27, 895-910, 1991.

Lyman, W. J., W. F. Reehl, and D. H. Rosenblatt, Handbook of Chemical Property Estimation Methods: Environmental Behavior of Organic Compounds, McGraw-Hill, New York, 1982.

Mabey, W. R., J. H. Smith, R. T. Podoll, H. L. Johnson, T. Mill, T. W. Chou, J. Gates, I. W. Partridge, H. Jaber, and D. Vandenberg, Aquatic fate process data for organic priority pollutants, Rep. 440/4-81-014, Environ. Prot. Agency, Washington, D. C., 1982.

Mendoza, C. A., and E. O. Frind, Advective-dispersive transport of dense organic vapors in the unsaturated zone, 1, Model development, Water Resour. Res., 26, 379-387, 1990.

Mendoza, C. A., and T. A. McAlary, Modeling of ground-water contamination caused by organic solvent vapors, Ground Water, 28, 199-206, 1990.

Millington, R. J., Gas diffusion in porous media, Science, 130 , $100-102,1959$.

Pionke, H. B., and D. W. Glotfelty, Contamination of groundwater by atrazine and selected metabolites, Chemosphere, $21,813-822$, 1990.

Rajaram, H., and L. W. Gelhar, Three-dimensional spatial moments analysis of the Borden tracer test, Water Resour. Res., 27, 1239-1251, 1991.

Sleep, B. E., and J. F. Sykes, Modeling the transport of volatile organics in variably saturated media, Water Resour. Res., 25, $81-92,1989$.

Swallow, J. A., and P. M. Gschwend, Volatilization of organic compounds from unconfined aquifers, paper presented at NWWA/API Third National Symposium on Aquifer Restoration and Groundwater Monitoring, Natl. Water Well Assoc./Am. Pet. Inst., Columbus, Ohio, May 1983.

R. L. Johnson, Department of Environmental Science and Engineering, Center for Groundwater Research, Oregon Graduate Institute, 19600 Northwest vonNeumann Drive, Beaverton, OR 970061999.

K. A. McCarthy, Water Resources Division, U.S. Geological Survey, 10615 Southeast Cherry Blossom Drive, Portland, OR 97216.

(Received October 20, 1992; revised December 22, 1992; accepted January 8, 1993.) 